University of Nebraska - Lincoln

DigitalCommons@University of Nebraska - Lincoln

Mechanical \& Materials Engineering Faculty

Publications

Mechanical \& Materials Engineering

Department of

2006

\title{
Modeling, Analysis, and Experimental Study of In Vivo Wheeled Robotic Mobility
}

\author{
Mark E. Rentschler \\ University of Nebraska Medical Center \\ Jason Dumpert \\ University of Nebraska-Lincoln \\ Stephen R. Platt \\ University of Nebraska-Lincoln, splatt2@unl.edu \\ Karl lagnemma \\ Massachusetts Institute of Technology \\ Dmitry Oleynikov \\ University of Nebraska Medical Center \\ See next page for additional authors
}

Follow this and additional works at: https://digitalcommons.unl.edu/mechengfacpub

Part of the Mechanical Engineering Commons

Rentschler, Mark E.; Dumpert, Jason; Platt, Stephen R.; Iagnemma, Karl; Oleynikov, Dmitry; and Farritor, Shane M., "Modeling, Analysis, and Experimental Study of In Vivo Wheeled Robotic Mobility" (2006). Mechanical \& Materials Engineering Faculty Publications. 16.

https://digitalcommons.unl.edu/mechengfacpub/16

This Article is brought to you for free and open access by the Mechanical \& Materials Engineering, Department of at DigitalCommons@University of Nebraska - Lincoln. It has been accepted for inclusion in Mechanical \& Materials Engineering Faculty Publications by an authorized administrator of DigitalCommons@University of Nebraska Lincoln. 


\section{Authors}

Mark E. Rentschler, Jason Dumpert, Stephen R. Platt, Karl lagnemma, Dmitry Oleynikov, and Shane M. Farritor 


\title{
Modeling, Analysis, and Experimental Study of In Vivo Wheeled Robotic Mobility
}

\author{
Mark E. Rentschler, Jason Dumpert, Stephen R. Platt, Karl Iagnemma, Dmitry Oleynikov, and Shane M. Farritor
}

\begin{abstract}
Laparoscopy is abdominal surgery performed with long tools inserted through small incisions. The use of small incisions reduces patient trauma, but also eliminates the surgeon's ability to view and touch the surgical environment directly. These limitations generally restrict the application of laparoscopy to procedures less complex than those performed during open surgery. This paper presents a theoretical and experimental analysis of miniature, wheeled, in vivo robots to support laparoscopy. The objective is to develop a wireless mobile imaging robot that can be placed inside the abdominal cavity during surgery. Such robots will allow the surgeon to view the surgical environment from multiple angles. The motion of these in vivo robots will not be constrained by the insertion incisions. Simulation and experimental analyses have led to a wheel design that can attain good mobility performance in in vivo conditions.
\end{abstract}

Index Terms - In vivo, laparoscopy, liver biomechanics, surgical robots, wheeled mobility.

\section{INTRODUCTION}

A PRIMARY advantage of minimally invasive surgery is the use of small incisions, compared with conventional open surgery. These small incisions reduce patient trauma. However, they do not allow the surgeon to view or touch the surgical environment directly, and they constrain the motion of the endpoint of the tools and cameras to spherical arcs whose center is the insertion point. Vision limitations are significant [1], [2] because the current field of view cannot encompass the frequent changes of instruments as they pass through the abdominal cavity. This has led to accidental injury to organs and vascular structures [3], [4]. Additional viewpoints, showing the entire body cavity, would be helpful [5]. Such limitations have slowed the expanded use of laparoscopic techniques. Within about one decade of the first laparoscopic cholecystectomy, $85 \%$ of all gallbladder excisions were performed laparoscopically [6]. The overwhelming success of this procedure resulted in high expectations for the rapid, wholesale conversion of many other conventionally open procedures to less invasive approaches. The reality is that laparoscopic surgery has not realized this potential. For example,

Manuscript received July 25, 2005. This paper was recommended for publication by Associate Editor J. Troccaz and Editor I. Walker upon evaluation of the reviewers' comments.

M. E. Rentschler and D. Oleynikov are with the University of Nebraska Medical Center, Omaha, NE 68198 USA (e-mail: mrentsch@bigred.unl.edu; doleynik@unmc.edu).

J. Dumpert, S. R. Platt, and S. M. Farritor are with the Mechanical Engineering Department, University of Nebraska, Lincoln, NE 68588 USA (e-mail: jdumper1@bigred.unl.edu; srp@unlserve.unl.edu; sfarritor@unl.edu).

$\mathrm{K}$. Iagnemma is with the Mechanical Engineering Department, Massachusetts Institute of Technology, Cambridge, MA 02139 USA (e-mail: kdi@ mit.edu).

Digital Object Identifier 10.1109/TRO.2005.862490

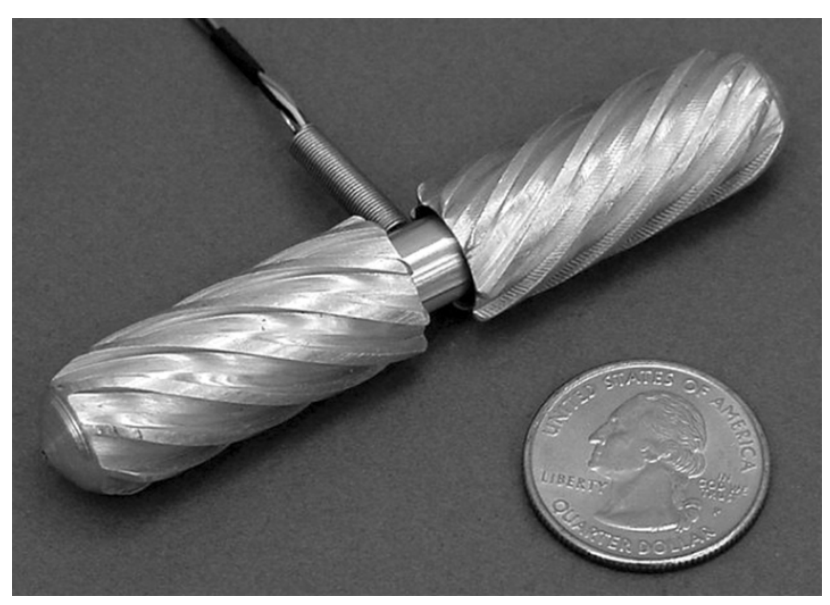

Fig. 1. In vivo wheeled robot prototype is $15 \mathrm{~mm}$ in diameter and $85 \mathrm{~mm}$ long. Here it is shown with a tether to supply power.

in 2000, less than $3 \%$ of colon resections [7] and only $17 \%$ of cardiothoracic surgeries [6] were performed laparoscopically.

Several robot systems exist to help increase the surgeon's dexterity by precisely manipulating laparoscopic tools. Such systems generally consist of a multiarm robot that is external to the patient. Each arm manipulates a tool (or camera) that is teleoperated by a surgeon. The robots can filter the natural tremor present in the human hand, correct for the effects of motion reversal, and/or perform motion scaling to provide greater instrument control. Such systems are generally large, expensive, and have limited motion because they are still constrained by the insertion points.

A potentially new approach to laparoscopy involves inserting miniature robotic assistants entirely into the patient. Such in vivo robots will provide vision and task assistance without being constrained by the entry incision.

The robot being analyzed in this paper, shown in its nominal configuration in Fig. 1, is a cylinder that is $15 \mathrm{~mm}$ in diameter and $85 \mathrm{~mm}$ long. It has two wheels that are independently driven, and a small appendage is attached to prevent the body from spinning. It has a small central region that is sized to hold a camera. Entry into the abdominal cavity is gained through a traditional trocar port. The robot can currently be removed with laparoscopic tools using only one port (entry port).

These types of in vivo robots will need to traverse the abdominal organs without causing damage. Mobility is difficult because the environment is slick, hilly, and deformable. This paper describes work to create wheel designs that provide sufficient traction without causing tissue damage. Wheel design has been improved through viscoelastic modeling, laboratory experimentation, and in vivo testing. 

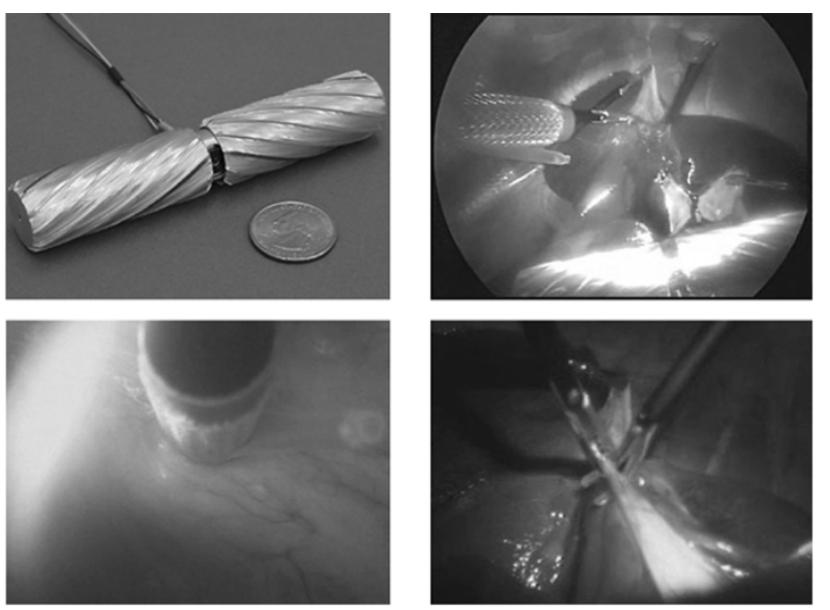

Fig. 2. Mobile adjustable-focus camera robot (upper left) as viewed from the laparoscope during cholecystectomy (upper right). View of the trocar port (bottom left) and gall bladder (bottom right) from the robot.

During routine laparoscopic procedures, grasping forces as high as $40 \mathrm{~N}$ have been recorded [8], with corresponding tissue pressure of approximately $400 \mathrm{kPa}$. The in vivo robot crawler weighs only $0.30 \mathrm{~N}$, and is capable of producing a maximum drawbar force of approximately $0.30 \mathrm{~N}$. This weight corresponds to an approximate tissue pressure of $470 \mathrm{~Pa}$. While conventional grasping forces are high enough to cause tissue damage, it is expected that in vivo robot tissue damage will be negligible, compared with conventional procedures.

To demonstrate the practical applicability of this approach to surgery, the successful wheel design described in this paper was used to create a wheeled robot with an adjustable-focus camera (Fig. 2, upper left). This mobile robotic camera system was tested in vivo in a porcine model [9], and used to explore the abdominal cavity. It also provided the only visual feedback used by a surgeon during a cholecystectomy (gall bladder removal) as shown in Fig. 2, right. By inserting such a mobile camera robot into the abdominal cavity through one of the standard laparoscopic tool ports, the traditional third camera port could be eliminated. This would reduce patient trauma, and has the potential to improve laparoscopy compared with current systems. The long-term goal of this work is to create a team of in vivo robots that could serve as surgical assistants and/or replace traditional laparoscopic tools.

This paper presents a theoretical and experimental analysis of in vivo wheeled mobility. Previous work is reviewed, and then a detailed viscoelastic model of the wheel/tissue interaction is presented. This model is then verified in laboratory experiments, and several wheel designs are evaluated. Finally, the results of in vivo experiments are presented.

\section{LITERATURE REVIEW}

\section{A. Robot-Assisted Endoscopy}

The use of robotics is currently recognized as the major driving force for the future technological advance of minimally invasive surgery [10]-[12]. The first application of robotics to laparoscopic surgery was the Automated Endoscopic System for Optimal Positioning (AESOP), which allowed the surgeon to position and stabilize a laparoscopic camera using voice control [13]. This was the first robotic device to receive approval from the Food and Drug Administration (FDA) for clinical use in abdominal surgery [11], and it successfully launched the era of robot-assisted surgery [10]. The da Vinci Surgical System (Intuitive Surgical) is a current, commercially available telerobotic device. Da Vinci, and similar robots, serve in a master-slave relationship with the surgeon, and use separate arms to hold a camera and the surgical instruments. Computerized control systems are used to filter the natural tremor present in the human hand, correct for the effects of motion reversal, and perform motion scaling to provide greater control of instrument movements in the surgical field. Such systems have been available for only a few years, and their efficacy and value are currently being evaluated in randomized clinical trials [10]. Other master/slave robots similar to da Vinci have been developed (e.g., ARTEMIS, ZEUS), but none has yet seen da Vinci's widespread application. Other research has focused on tool designs and end-effectors that restore some of the lost dexterity by including a wrist-like joint [14].

Hirose and Breedveld have developed a steerable endoscope that can rotate left to right $60^{\circ}$ and up $180^{\circ}$ [15], while the commercially available Olympus endoscope can rotate left to right $100^{\circ}$, down $90^{\circ}$, and up $120^{\circ}$. These systems have not been widely accepted for abdominal laparoscopic surgery as surgeons have found them disorienting and difficult to use. These scopes, while increasing the available visual field, remain limited by range of actuation. Providing in vivo robotic visual feedback allows the surgeon to see the entire visual field, including looking back at the entry port to assist trocar and tool insertion. Further, in vivo robotic camera feedback eliminates the need for the laparoscope incision.

All of the above systems that are implemented from outside the body are still fundamentally constrained by the limited access to the abdominal cavity provided by small access incisions. Moreover, each of the robotic arms is necessarily long and bulky to accommodate the range of motion required to maneuver the long instruments attached to each arm. Large excursion arcs of the arms lead to collisions outside the patient, and improper placement of the access ports leads to collisions inside the patient [11]. Each arm requires a separate access port; hence, the number of incisions is not reduced, compared with traditional nonrobotic laparoscopy. These incisions are made as part of the set-up procedure for the robot, so the problems associated with injuries caused by access port insertion remain unaddressed. Similarly, a limited range of motion for the robotic camera can still result in obstructed or incomplete visual feedback. Tool changes still require the removal of the existing tool and the reinsertion of the new one, adding to the overall surgical time and adversely affecting the efficiency of the operation [14], [16].

Several in vivo devices have been developed to assist during surgical procedures. The Heartlander robot was developed to crawl on the heart during cardiac surgery [17], while other locomotion devices have been designed to assist with gastrointestinal procedures [18]. These devices address fundamentally different problems than those of the abdominal cavity. The Heartlander robot was designed to provide a stabilized platform for heart manipulation. Robots designed to navigate the 
gastrointestinal tract are confined to a tube, which is used to assist motion.

Initial work has begun to address abdominal in vivo robotic manipulators and visual feedback [19]. Several fixed-base prototype in vivo camera robots have been used during porcine (swine) cholecystectomies to provide the surgeon with additional visual feedback [20]. While these fixed-base robots are fundamentally different from the mobile robot described in this paper, the successful clinical trials, with the fixed-base robots, demonstrated that in vivo robotic cameras can provide useful and improved visual feedback. A quantitative comparison of several visual parameters (contrast, resolution) has been made between these cameras and a standard laparoscope [21]. Image quality from these robot cameras has been found to be comparable to current laparoscopic systems.

\section{B. Wheeled Mobility}

A wheeled mobile robot moving inside an abdominal cavity can be viewed in the general context of wheel-surface interaction. Wheel-surface interaction has been studied extensively for passenger vehicle applications. For the present application, the surfaces of interest are terrains with surface properties that range from near-rigid to highly deformable. First attempts to develop a comprehensive theory applicable to all terrains were made at the Land Locomotion Laboratory [22]. In 1967, Onafeko and Reece developed an improved theory for including shear stress with wheel slip during wheel-soil interaction [23]. Wong and Reece (1967) showed that there are both radial and tangential stresses on the wheel-soil interface [24]. It was also shown that these do not only depend on soil properties and wheel dimensions, but wheel slip, as well. Additional work has used analytical models to approximate wheel/soil interaction [25], [26], as well as finite element methods [27], [28].

Although the above studies can yield insight into the wheel-tissue interaction phenomena, the surface inside the abdomen possesses several key differences from most terrestrial terrains. The internal organs can be highly deformable and very slick, and the constitutive relations describing wheel-organ interaction are quite different from those of soils. In addition, the tissue membrane can bear significant tensile forces, which is generally not possible for deformable soils. Also, the surface deformation under the weight of the robot in Fig. 1 can be high, sometimes even larger than the wheel diameter. Thus dedicated tissue models are required to accurately model tissue-terrain interaction.

\section{Tissue Mechanics}

Human organs are highly deformable and have highly variable surface properties, leading to a difficult navigational environment for a small robot. Any successful mobile robot must also traverse these organs without causing damage.

Previous work has focused on identifying mechanical properties of biological tissues. Ultrasound has been used to identify the elastic nature of soft tissues [29]. Measurements of Young's modulus have been made of healthy and diseased human livers to correlate with pathological findings [30]. Soft biological tissues have also been tested in extension to identify mechanical

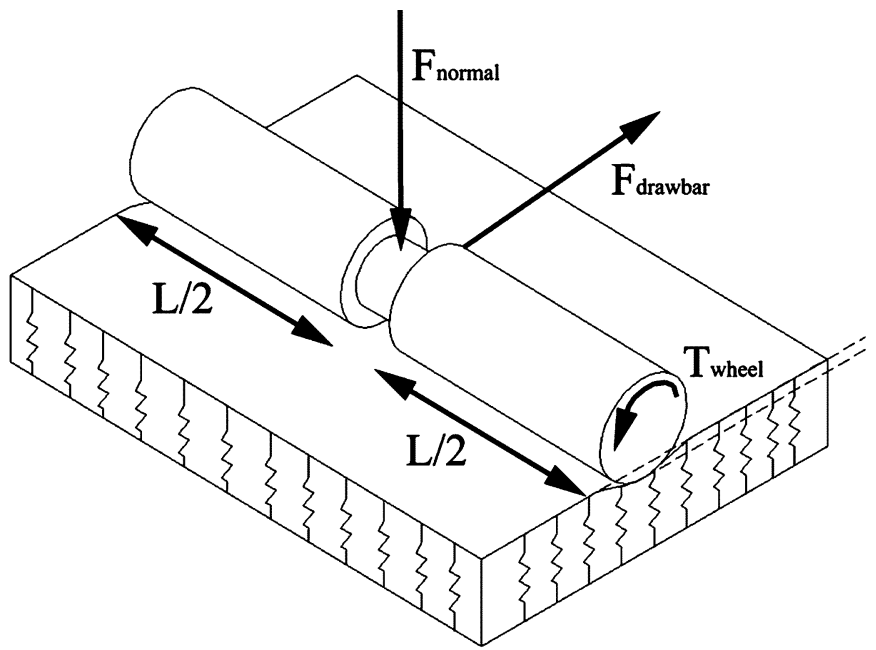

Fig. 3. Three-dimensional robot model, where the drawbar force is a strong function of the normal force, wheel torque, and effective coefficient of friction between the wheel and the surface.

properties [31]. The findings of these studies show that biological tissue is generally not elastic, but rather viscoelastic, although modeling tissue as elastic media has had some success in predicting response in solid organs.

Modeling of biological tissues has included using the theory of porous media to develop a biphasic model [32]. Hysteresis, common to soft tissues, has been accurately predicted using a three-dimensional nonlinear model [33].

Other work has studied tissue mechanics and properties as they interact with surgical tools to develop improved haptic environments. A force-feedback surgical grasper has been developed that is used to measure mechanical properties of tissue [34]. Results include the in vivo compressive properties of porcine abdominal soft tissues [35]. Similarly, the forces required to dissect livers have been measured [36]. This has led to modeling a local effective Young's modulus. In addition, the forces applied and resulting displacements of the mesocolon have been recorded during colon surgery to aid in designing safer laparoscopic graspers [37].

\section{Elastic TISsue Model}

As depicted in Fig. 3, the mobility of a wheeled robot can be characterized by the drawbar force $\left(F_{\text {drawbar }}\right)$ produced over a given medium under given loading conditions and velocities. This force is a strong function of the normal force $\left(F_{\text {normal }}\right)$ between the wheel and the surface, the effective coefficient of friction between the wheel and the surface, and wheel torque $\left(\tau_{\text {wheel }}\right)$ [24].

The surface mobility of in vivo robots was previously modeled [38] using the surface interaction model of Filonenko-Borodich [39] for a membrane on an elastic foundation.

This elastic model, shown in Fig. 4, was used to analyze wheel designs for in vivo wheeled mobility. However, predicted drawbar forces, as outlined in Section VII, were much larger than observed forces for several reasons. First, this elastic approximation assumed that the tension in the membrane could be neglected, which is a reasonable assumption for small strains. 


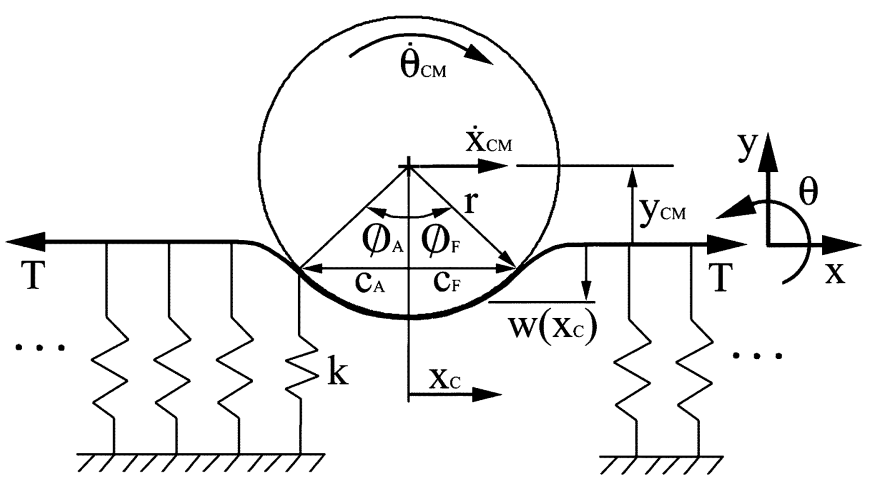

Fig. 4. Elastic tissue model where $k$ is the tissue stiffness.

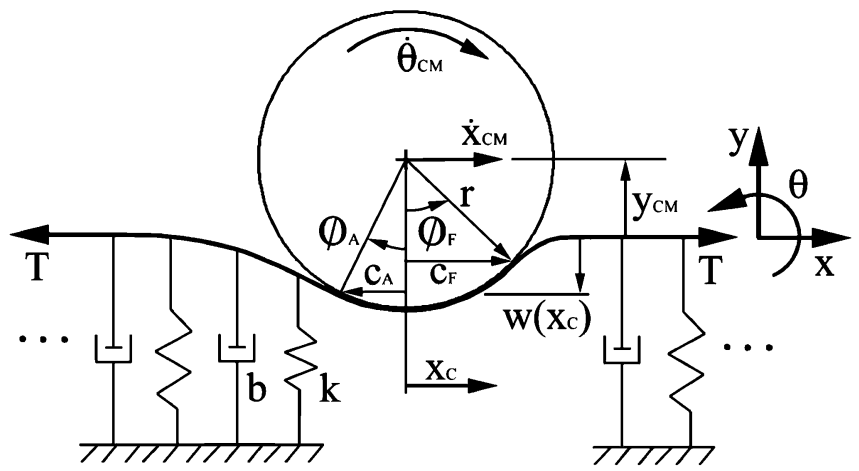

Fig. 5. Viscoelastic model, where $k$ is the tissue stiffness and $b$ is the viscous damping of the tissue.

However, for larger deflections, the membrane tension contributes significantly to the restoring force of the organ. Next, biological tissue usually does not display elastic properties, but instead is viscoelastic [40]. Therefore, the energy loss due to the viscous nature of the biological tissue was not captured by this elastic model.

\section{Viscoelastic Tissue Model}

A viscoelastic biological tissue model is used to study the wheel/tissue interaction in this paper. The model presented uses a traditional Voight viscoelastic model [40] covered by a membrane in tension (Fig. 5). Here, $k$ is the tissue "stiffness, " $b$ is the tissue "damping," $w$ is the deflection of the surface, and $T$ is the membrane tension. "Stiffness" is expressed in this paper as a ratio of surface pressure per unit displacement, (i.e., the force applied over a given surface area per vertical displacement). "Damping" is expressed as a ratio of surface pressure per unit displacement rate (i.e., the force applied over a given surface area per vertical displacement rate). The robot mass $(m)$, wheel radius $(r)$, wheel length $(L)$, wheel rotation velocity $\left(\dot{\theta}_{c m}\right)$, and wheel translational velocity $\left(\dot{x}_{c m}\right)$ are assumed to be known parameters. Calculations are performed per unit robot length $(L)$. The vertical wheel position $\left(y_{C M}\right)$, contact angle $\left(\varphi_{F}\right)$, and length in front of the wheel $\left(c_{F}\right)$, fore, contact angle $\left(\varphi_{A}\right)$, and length behind the wheel $\left(c_{A}\right)$, aft, tissue deflection $(w)$, and drawbar force $\left(F_{\text {drawbar }}\right)$ are unknown. The contact lengths $(c)$ are related to the wheel radius $(r)$ by the sine of the contact angle $(\varphi)$. The parameters $\left(\varphi_{A}\right)$ and $\left(c_{A}\right)$ are negative.

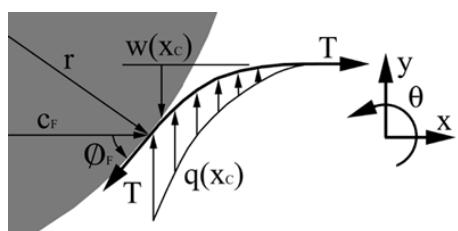

Fig. 6. Exponential decay of the membrane profile in front of the rolling wheel (shaded region), where $\phi_{F}$ is the same angle as in Fig. 5.

\section{A. Membrane Forces}

From experimental observations, the deflection profile of the membrane in front of the rolling wheel is approximated as a decaying exponential function in the $x$-direction, as shown in Fig. 6, where $q\left(x_{C}\right)$ is the tissue pressure. The tissue deflection $w(x)$ for this region is of the form

$$
w\left(x_{C}\right)=A e^{B\left(x_{C}-c_{F}\right)}
$$

where the constants $A$ and $B$ are determined from the boundary conditions at the contact point $\left(\phi_{F}\right)$. From the wheel geometry at this point

$$
\begin{aligned}
w\left(x_{C}=c_{F}\right) & =\sqrt{r^{2}-c_{F}^{2}}-y_{C M} \\
& =r \cos \left(\phi_{F}\right)-y_{C M} \\
\frac{d w\left(x_{C}=c_{F}\right)}{d x_{C}} & =\frac{-c_{F}}{\sqrt{r^{2}-c_{F}^{2}}} \\
& =-\tan \left(\phi_{F}\right) .
\end{aligned}
$$

From (1) and (2) at $x_{C}=c_{F}$

$$
\begin{aligned}
A & =\sqrt{r^{2}-c_{F}^{2}}-y_{C M} \\
& =r \cos \left(\phi_{F}\right)-y_{C M} \\
B & =\frac{-c_{F}}{\sqrt{r^{2}-c_{F}^{2}}\left(\sqrt{r^{2}-c_{F}^{2}}-y_{C M}\right)} \\
& =\frac{-\tan \left(\phi_{F}\right)}{r \cos \left(\phi_{F}\right)-y_{C M}} .
\end{aligned}
$$

The deflection profile rate, along this exponential decay, is of the form

$$
\begin{aligned}
\dot{w}\left(x_{C}\right) & =\frac{d w\left(x_{C}\right)}{d t} \\
& =\frac{\partial w\left(x_{C}\right)}{\partial x_{C}} \frac{\partial x_{C}}{\partial t} \\
& =\left(A B e^{B\left(x_{C}-c_{F}\right)}\right)\left(-\dot{x}_{C M}\right) \\
& =-\dot{x}_{C M} A B e^{B\left(x_{C}-c_{F}\right)} .
\end{aligned}
$$

Summation of the vertical forces along this area in front of the wheel (Fig. 6) leads to the following relationship:

$$
\begin{aligned}
& T \sin \left(\phi_{F}\right) \\
& =L \int_{c_{F}}^{\infty} q\left(x_{C}\right) d x_{C} \\
& =L \int_{c_{F}}^{\infty}\left(k\left(A e^{B\left(x_{C}-c_{F}\right)}\right)\right. \\
& \left.\quad+b\left(-\dot{x}_{C M} A B e^{B\left(x_{C}-c_{F}\right)}\right)\right) d x_{C} \\
& =\frac{k L\left(r \cos \left(\phi_{F}\right)-y_{C M}\right)^{2}}{\tan \left(\phi_{F}\right)} \\
& \quad+L b \dot{x}_{C M}\left(r \cos \left(\phi_{F}\right)-y_{C M}\right) .
\end{aligned}
$$




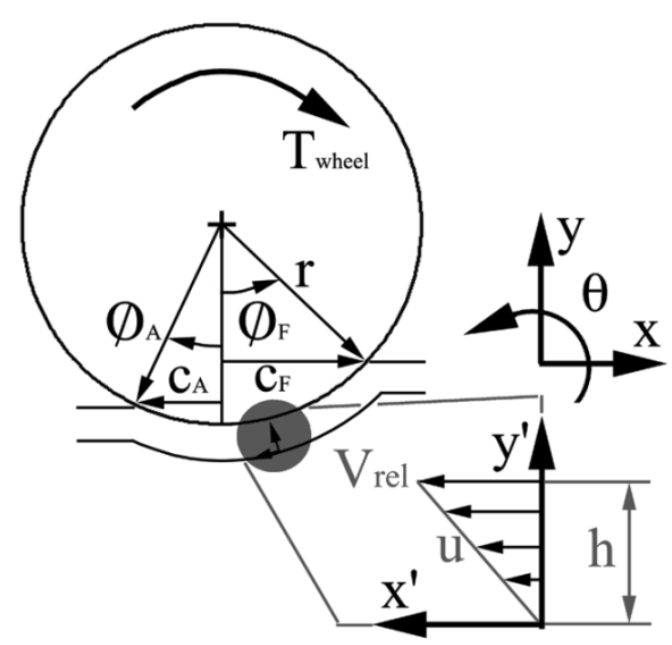

Fig. 7. Peritoneal fluid model where the fluid thickness is exaggerated. The second coordinate system is a zoomed-in view of the fluid layer.

A second similar relationship is established at the trailing (aft) contact point $\left(\phi_{A}\right)$. The major difference in tissue deformation geometry between the elastic and viscoelastic models, for rolling motion, is that in the viscoelastic model, the trailing edge (aft) loses contact with the wheel more quickly than in the elastic case, due to the viscoelastic nature of the model (i.e., $\left.\left|\phi_{F}\right|>\left|\phi_{A}\right|\right)$. This feature reduces the positive drawbar force and was observed in laboratory tests. At the trailing edge, the deflection and deflection rate of the tissue are

$$
\begin{aligned}
w\left(x_{C}=c_{A}\right) & =\sqrt{r^{2}-c_{A}^{2}}-y_{C M} \\
& =r \cos \left(\phi_{A}\right)-y_{C M} \\
\dot{w}\left(x_{C}=c_{A}\right) & =\frac{c_{A}}{\sqrt{r^{2}-c_{A}^{2}}} \dot{x}_{C M} \\
& =\dot{x}_{C M} \tan \left(\phi_{A}\right) .
\end{aligned}
$$

Also, the pressure applied to the wheel is equal to zero at this aft contact point

$$
q\left(x_{C}=c_{A}\right)=k w\left(c_{A}\right)+b \dot{w}\left(c_{A}\right)=0 .
$$

Substituting (6) into (7) creates a second relationship between the vertical wheel position $\left(y_{C M}\right)$, the contact angle in front of the wheel $\left(\phi_{F}\right)$, and contact angle behind the wheel $\left(\phi_{A}\right)$, given by

$$
k\left(r \cos \left(\phi_{A}\right)-y_{C M}\right)=-b\left(\dot{x}_{C M} \tan \left(\phi_{A}\right)\right) .
$$

\section{B. Shear Forces}

The motion of the robot depends on the drawbar force (related to forward acceleration) generated by the interaction between the wheel and the peritoneal fluid that coats the organs (Fig. 7). A Reynolds number of approximately 9.5 for the fluid flow between the wheel and organ was determined by approximating the peritoneal fluid's density and viscosity as that of water, with a maximum speed of the wheel relative to the tissue of $1.3 \mathrm{~cm} / \mathrm{s}$ ( $S R=0.23$, as defined in Section V). Therefore,

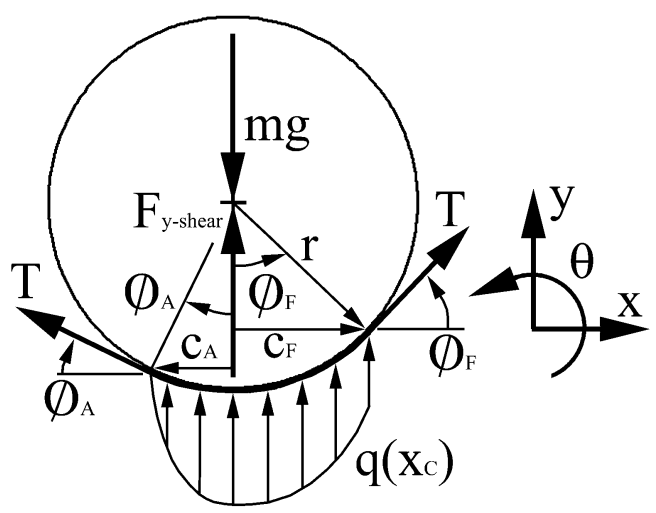

Fig. 8. Vertical forces acting on the wheel for the viscoelastic model. The pressure due to tissue deformation is shown, in addition to the vertical component of shear force, membrane tension, and robot weight.

this flow can generally be considered viscous [41]. The shear stress at the wheel $\left(\tau_{x^{\prime} y^{\prime}}\right)$ is described by

$$
\tau_{x^{\prime} y^{\prime}}=\mu \frac{\partial u}{\partial y^{\prime}}=\mu \frac{V_{\text {rel }}}{h}
$$

where $x^{\prime}$ and $y^{\prime}$ are local axes, $\mu$ is the viscosity of the fluid, and $u\left(y^{\prime}\right)$ is the velocity profile of the fluid between the wheel and the organ. A linear velocity profile is assumed, where $V_{\text {rel }}$ is the relative velocity between the wheel surface and the organ, and $h$ is the distance between the wheel and the organ. The distance $h$ is assumed to be constant, and $\mu / h$ is estimated as described in Section V-C. $V_{\text {rel }}$ is given by

$$
V_{\text {rel }}=-r \dot{\theta}_{c m}-\dot{x}_{c m} \cos \phi
$$

where $\dot{\theta}_{c m}$ is the rotational velocity of the wheel (negative), and $\dot{x}_{c m}$ is the velocity of the center of mass in the horizontal direction.

\section{Equations of Motion}

The vertical forces acting on the wheel (Fig. 8) are due to the vertical components of the shearing of a peritoneal fluid layer between the wheel and tissue $\left(F_{y-\text { shear }}\right)$, the viscoelastic tissue pressure $(q)$, and the membrane tension $(T)$. The forces in the vertical direction can be summed to yield

$m \ddot{y}_{C M}=-m g+F_{y-\text { shear }}+F_{y-\text { pressure }}+F_{y-\text { membrane }}$.

It is important to note that with this model, the tissue response fore and aft of the wheel is asymmetric. Thus, the vertical force developed from the shearing of the fluid between the wheel and the membrane is nonzero

$$
\begin{aligned}
F_{y-\text { shear }}= & \int_{\phi_{A}}^{\phi_{F}} L\left(\tau_{x^{\prime} y^{\prime}} \sin \phi\right) r \partial \phi \\
= & \frac{\mu}{h} L r^{2} \dot{\theta}_{c m}\left(\cos \left(\phi_{F}\right)-\cos \left(\phi_{A}\right)\right) \\
& +\frac{\mu}{2 h} L r \dot{x}_{c m}\left(\cos ^{2}\left(\phi_{F}\right)-\cos ^{2}\left(\phi_{A}\right)\right) .
\end{aligned}
$$

The vertical force due to membrane tension is

$$
F_{y-\text { membrane }}=T\left(\sin \left(\phi_{F}\right)-\sin \left(\phi_{A}\right)\right)
$$


and the vertical force due to tissue pressure is

$$
\begin{aligned}
F_{y} \text { - pressure } & \\
= & L \int_{c_{A}}^{c_{F}} q\left(x_{C}\right) d x_{C} \\
= & L \int_{c_{A}}^{c_{F}}\left(k w\left(x_{C}\right)+b \dot{w}\left(x_{C}\right)\right) d x_{C} \\
= & L \int_{c_{A}}^{c_{F}}\left(k\left(\sqrt{r^{2}-x_{C}^{2}}-y_{C M}\right)\right. \\
& \left.+b\left(\frac{x_{C}}{\sqrt{r^{2}-x_{C}^{2}}} \dot{x}_{C M}\right)\right) d x_{C} \\
= & \operatorname{Lkr}\left(\frac{1}{2}\left(r \cos \left(\phi_{F}\right) \sin \left(\phi_{F}\right)+r \phi_{F}\right)-y_{C M} \sin \left(\phi_{F}\right)\right) \\
& -\operatorname{Lkr}\left(\frac{1}{2}\left(r \cos \left(\phi_{A}\right) \sin \left(\phi_{A}\right)+r \phi_{A}\right)-y_{C M} \sin \left(\phi_{A}\right)\right) \\
& +\operatorname{Lbr} \dot{x}_{C M}\left(\cos \left(\phi_{A}\right)-\cos \left(\phi_{F}\right)\right) .
\end{aligned}
$$

Using (5), (8), and (11), the contact angles $\left(\phi_{A}\right)$ and $\left(\phi_{F}\right)$ and the vertical position of the center of mass $\left(y_{C M}\right)$ are determined numerically. Using these parameter values, the drawbar force can be determined. The forces acting on the wheel in the $x$-direction are shown in Fig. 9, and the horizontal equation of motion is

$m \ddot{x}_{C M}=-F_{\text {drawbar }}+F_{x-\text { shear }}+F_{x-\text { pressure }}+F_{x-\text { membrane }}$

The shear stress can be projected along the horizontal axis to estimate the horizontal force generated by the wheel/organ interaction, given by

$$
\begin{aligned}
F_{x \text {-shear }}= & \int_{\phi_{A}}^{\phi_{F}} L\left(\tau_{x^{\prime} y^{\prime}} \cos \phi\right) r \partial \phi \\
= & \frac{\mu}{h} L r^{2} \dot{\theta}_{c m}\left(\sin \left(\phi_{A}\right)-\sin \left(\phi_{F}\right)\right) \\
& +\frac{\mu}{2 h} \operatorname{Lr} \dot{x}_{c m}\left(\phi_{A}-\phi_{F}\right) \\
& +\frac{\mu}{4 h} \operatorname{Lr} \dot{x}_{c m}\left(\sin \left(2 \phi_{A}\right)-\sin \left(2 \phi_{F}\right)\right) .
\end{aligned}
$$

The horizontal pressure from the tissue, and the resultant force from the membrane tension, is also nonzero due to the asymmetry caused by the viscoelastic response. The effect of the tension in the membrane is

$$
F_{x-\text { membrane }}=T\left(\cos \left(\phi_{F}\right)-\cos \left(\phi_{A}\right)\right) .
$$

The effect of the viscoelastic tissue on the horizontal motion can also be determined. It is assumed that the resultant tissue reaction force is radial to the wheel, and therefore, (14) can be

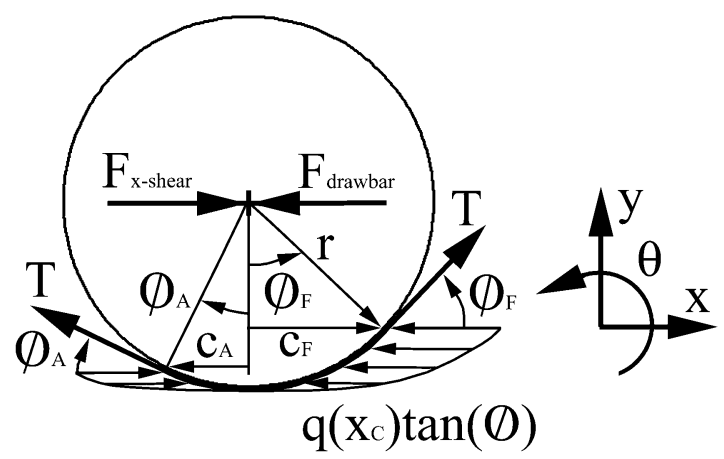

Fig. 9. Horizontal forces acting on the wheel for the viscoelastic model. The pressure due to tissue deformation is shown, in addition to the drawbar force, horizontal component of shear force, and membrane tension.

modified as follows:

$$
\begin{aligned}
F_{x-\text { pressure }}= & -L \int_{\phi_{A}}^{\phi_{F}} \frac{q(\phi)}{\cos (\phi)} r \sin (\phi) d \phi \\
= & -L r \int_{\phi_{A}}^{\phi_{F}} \tan (\phi)(k w(\phi)+b \dot{w}(\phi)) d \phi \\
= & -L r \int_{\phi_{A}}^{\phi_{F}} \tan (\phi)(k(r \cos (\phi) \\
& \left.\left.-y_{C M}\right)+b\left(\tan (\phi) \dot{x}_{C M}\right)\right) d \phi \\
= & -L k r\left(r\left(\cos \left(\phi_{A}\right)-\cos \left(\phi_{F}\right)\right)\right. \\
& \left.+y_{C M}\left(\log \left(\cos \left(\phi_{F}\right)\right)-\log \left(\cos \left(\phi_{A}\right)\right)\right)\right) \\
& -\operatorname{Lbr}_{C M}\left(\tan \left(\phi_{F}\right)\right. \\
& \left.-\tan \left(\phi_{A}\right)-\left(\phi_{F}\right)+\left(\phi_{A}\right)\right)
\end{aligned}
$$

\section{Model Analysis}

A numerical simulation has been developed that incorporates the analytical model described above to simulate wheel/tissue interaction. This simulation was verified with a series of experiments, as described in Section VII. Equations (5), (8), (11), and (15) were used to develop a representation of wheel mobility performance for a smooth wheel using the viscoelastic model (Fig. 10).

Results show that an increase in drawbar force is achieved by decreasing the normal force of the robot (i.e., weight) and by increasing the wheel diameter. This is because increasing the normal force leads to more sinkage, which in the viscoelastic case causes increased motion resistance due to the membrane asymmetry. This is not the case for the elastic model, where increasing the weight simply leads to smaller fluid layer thickness, which increases drawbar force. This suggests that drawbar force might be maximized by employing a large, lightweight robot. It should be noted that these analyses consider the case of a smooth wheel with no tread or grouser pattern. It is well known that treads and grousers can significantly affect mobility by changing contact pressure and mechanical interaction. Due to the difficulty in obtaining accurate theoretical models of treads and grousers, these effects were studied experimentally. 


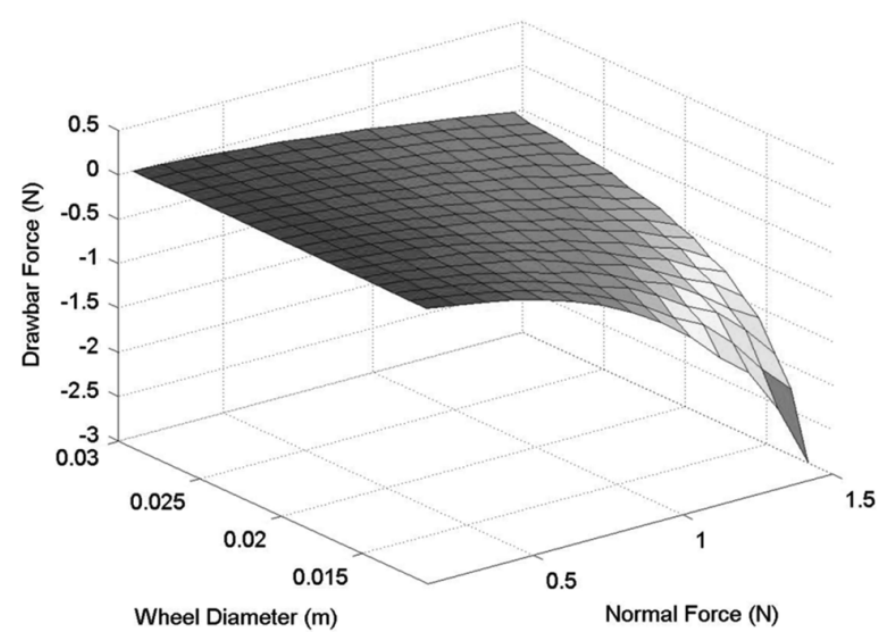

Fig. 10. Drawbar force as a function of the wheel diameter and the normal force for the viscoelastic model.

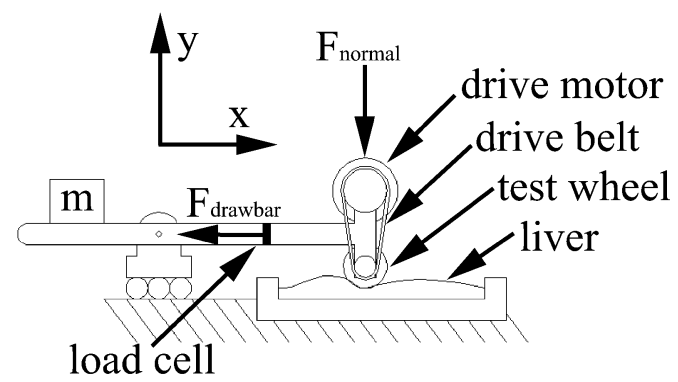

Fig. 11. Schematic of the experimental system used to test wheel performance in the lab.

\section{EXPERIMENTAL SYSTEM AND PARAMETER IDENTIFICATION}

\section{A. Experimental System}

1) Wheel-Tissue Interaction Platform: A laboratory system was created, as shown schematically in Fig. 11, to help validate our model and determine an effective wheel design that is capable of producing sufficient drawbar forces while minimizing tissue damage. This system is capable of actively and independently controlling the linear velocity and rotational velocity of the wheel. This allows wheel slip to be induced and the resulting drawbar force produced to be measured as the wheel, similar in size, shape, and material to the proposed robot, is moved across a model of an organ.

The system consists of a linear slide that moves a wheel assembly at a specified linear velocity. The slide is actuated with an independent motor. The wheel assembly is attached to the slide by a lever that is used to dictate the wheel/organ normal force. The rotational velocity of the wheel is independently controlled by a motor attached with a drive belt. A load cell, attached between the lever arm and the wheel assembly, is used to measure the drawbar force $F_{\text {drawbar }}$. An inclinometer on the lever is used to determine surface deflections.

2) Organ Model: The in vivo environment is very difficult to model. Excised, previously frozen, bovine (cow) liver was used to emulate the in vivo operating conditions mobile robots will experience. While this liver model does not capture all of the effects of the in vivo conditions, it has helped tremendously in leading toward a successful wheel design.

3) Experimental Procedure: A set of experiments was performed to study the mobility characteristics of wheels of varying diameter and geometry on bovine liver. In each experiment, the wheel assembly was driven across the bovine liver at a fixed linear velocity of $1.0 \mathrm{~cm} / \mathrm{s}$, while the angular velocity of the wheel was independently controlled at various slip ratios. The slip ratio is defined as

$$
\mathrm{SR}=1-\left|\frac{\dot{x}_{c m}}{r \dot{\theta}_{c m}}\right|
$$

where $\dot{\theta}_{c m}$ is the angular velocity of the wheel (negative), $\dot{x}_{c m}$ is the linear forward velocity of the center of mass of the wheel, and $r$ is the wheel radius.

The steady-state drawbar force was measured and averaged over a set of five tests for each slip ratio and applied normal force. The prototype robot weighs $0.30 \mathrm{~N}$, and the applied normal forces were $0.15,0.30$, and $0.45 \mathrm{~N}$. The test wheels have the same wheel length as the robot. Positive drawbar force indicates tension in the load cell (i.e., the wheel is pulling), while negative force indicates the load cell is in compression (i.e., the wheel is being pushed). The total distance traveled was approximately $12 \mathrm{~cm}$ during each test. Experiments were performed at slip ratios of $0,0.09,0.17$, and 0.23 , which represent a range of positive slip (pull) and no slip (at $\mathrm{SR}=0$ ).

\section{B. Liver Stiffness and Damping}

Experiments were performed to estimate the stiffness coefficient $k \mathrm{~N} / \mathrm{m}^{3}$, and damping coefficient $b \mathrm{Ns} / \mathrm{m}^{3}$ of the excised (previously frozen) bovine liver. This was accomplished by placing a rigid plate of known area on the bovine liver and measuring the vertical deflection as various weights were placed on the plate. Three separate sets of measurements were made with normal forces varying between 0.1 and $1.7 \mathrm{~N}$. The orientation of the plate was changed for each test to account for inhomogeneities in the material. The mass applied to the rigid plate was divided by the area of the plate to estimate the average applied pressure. The deflections were observed using a dial indicator with a resolution of $0.0254 \mathrm{~mm}$.

The deflections were not instantaneous. After each addition of weight, a steady-state deflection was used to determine the stiffness coefficient, while a linearized deflection rate was used to determine the damping coefficient.

Linear least-squares fits of the data were performed to determine the stiffness coefficient of the bovine liver, Fig. 12. The stiffness of the bovine liver was approximately $350000 \mathrm{~N} / \mathrm{m}^{3}$, while the damping coefficient was approximately $4000 \mathrm{Ns} / \mathrm{m}^{3}$.

These coefficients depend on the characteristic time of the measurements. Hours may be required to obtain a true steadystate deflection for a given applied stress. Here, the robot wheel, which is $1.5 \mathrm{~cm}$ in diameter, will traverse the abdominal organs at approximately $1 \mathrm{~cm} / \mathrm{s}$ for most applications. Therefore, the deflection of the bovine liver was measured for only several seconds, as the rolling wheel will be in contact with each point on the surface for this short time. 


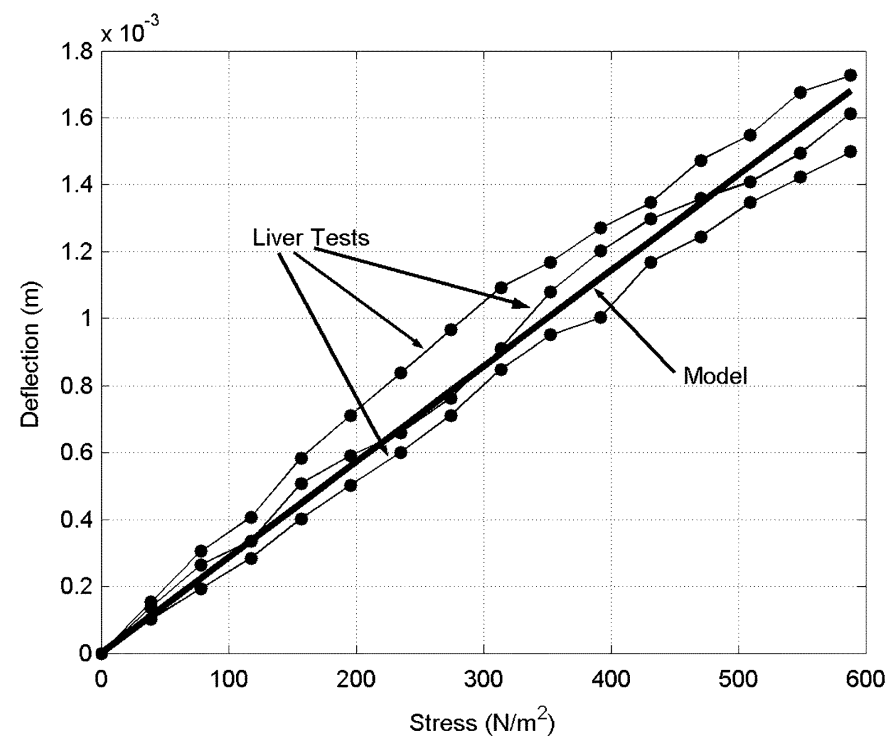

Fig. 12. Stiffness experiments for bovine liver. The best-fit model line is shown, along with the data from the three experiments.

\section{Peritoneal Fluid Viscosity}

Experiments were performed to estimate the viscous coefficient ratio $(\mu / h)$ in (12) and (16). During these experiments, the horizontal position of the wheel was held constant (no translation) while the wheel rotated on the surface of the organ model. The drawbar forces and the contact lengths $\left(\varphi_{F}, \varphi_{A}\right)$ were determined using the load cell and visual measurements from recorded video. Measurements were made for four different rotational velocities.

When the linear velocity is zero, the relative velocity between the wheel and the surface of the organ model equals the radial velocity of the wheel (10). The drawbar force $F_{\text {drawbar }}$ is also then equal to the horizontal component of the fluid shear load $F_{x \text {-shear }}$ from (15). The relationship between this shear force and the known wheel radial velocity can then be established using (15) and (16), allowing the ratio $(\mu / h)$ to be determined. This test was repeated five times for each of the four rotational velocities at each of three normal forces for the bovine liver organ model. The averaged viscosity ratio was determined to be $\mu / h=400 \mathrm{Ns} / \mathrm{m}^{3}$.

\section{Membrane Tension}

The tension in the membrane of the previously frozen bovine liver is small. However, in living tissues, this membrane tension is expected to be significant. For the bovine liver, the membrane tension is approximately $T=1.0 L \mathrm{~N}$, where $L$ is the length of the wheel in meters. This value was determined from physical observations of the deformed steady-state tissue geometry under several applied normal loads. The membrane tension was then approximated by summing vertical forces based on the measured liver stiffness and observed contact lengths along the wheel.

\section{EXPERIMENTAL RESULTS-SMOOTH WHEEL}

Experiments were performed on several sets of wheels using the linear slide platform. The smooth wheel data are presented in this section, while data from more complex wheel geometries are presented in Section VIII.

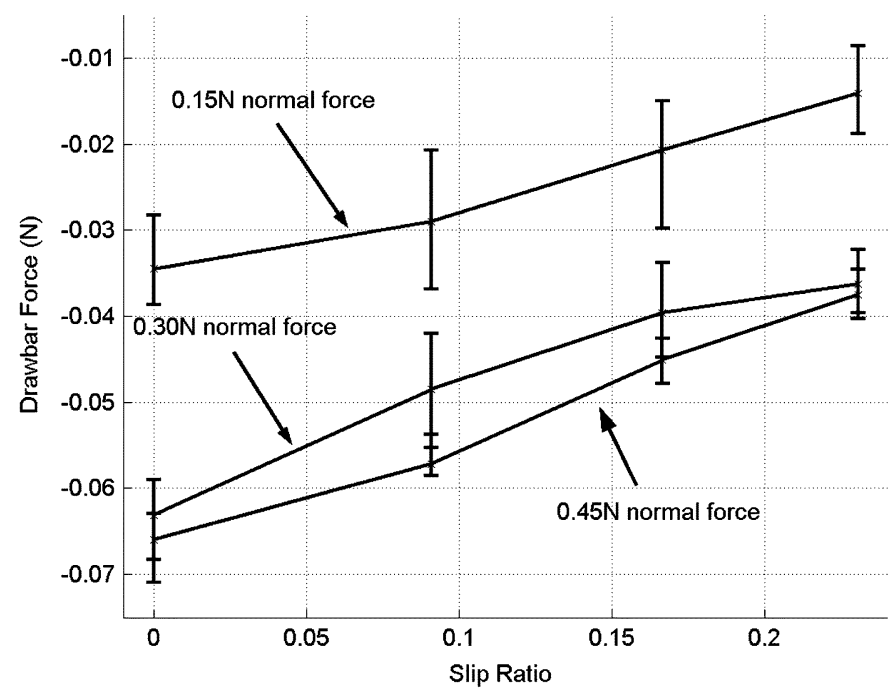

Fig. 13. Wheel experimental performance for the $15-\mathrm{mm}$ diameter smooth wheel.

\section{A. 15-mm Wheel}

Fig. 13 shows the experimental results obtained for the motion of a 15-mm diameter smooth aluminum wheel on the bovine liver. Four slip ratios were used, and three different normal forces were applied. All of the drawbar forces are negative, implying that the wheel produces no net traction, and that the linear slide is always pushing the wheel across the surface of the liver.

The negative drawbar forces measured by the experimental system indicate several things. First, the smooth wheel generates positive drawbar force due to fluid shearing. This force increases as the slip ratio increases, but is always exceeded by the motion resistance caused by viscoelastic liver deformation. This effect becomes more pronounced as the normal force increases, resulting in a larger normal pressure, and thus, greater sinkage.

\section{B. 20-mm Wheel}

Experimental results for a $20-\mathrm{mm}$ diameter smooth wheel are shown in Fig. 14. Like the 15-mm wheel, all of the drawbar forces are negative and increase with increasing slip ratio. Drawbar forces are more negative for the low slip ratios, but at higher slip ratios, the drawbar forces more closely approach zero, compared with the $15-\mathrm{mm}$ wheel. This suggests that increasing the wheel diameter for a fixed load reduces the effect of motion resistance due to viscoelastic liver deformation. This is due to the reduced normal pressure and similarly reduced sinkage.

Experiments were also performed on 25- and 30-mm diameter wheels. Similar trends to the smaller diameter wheels were observed.

\section{COMPARISON OF EXPERIMENTAL RESUlTS WITH THE ElASTIC AND ViscoElastic MODELS}

The analytical elastic model and viscoelastic model, as described in Sections III and IV, were used to determine expected drawbar forces for the smooth wheels. 


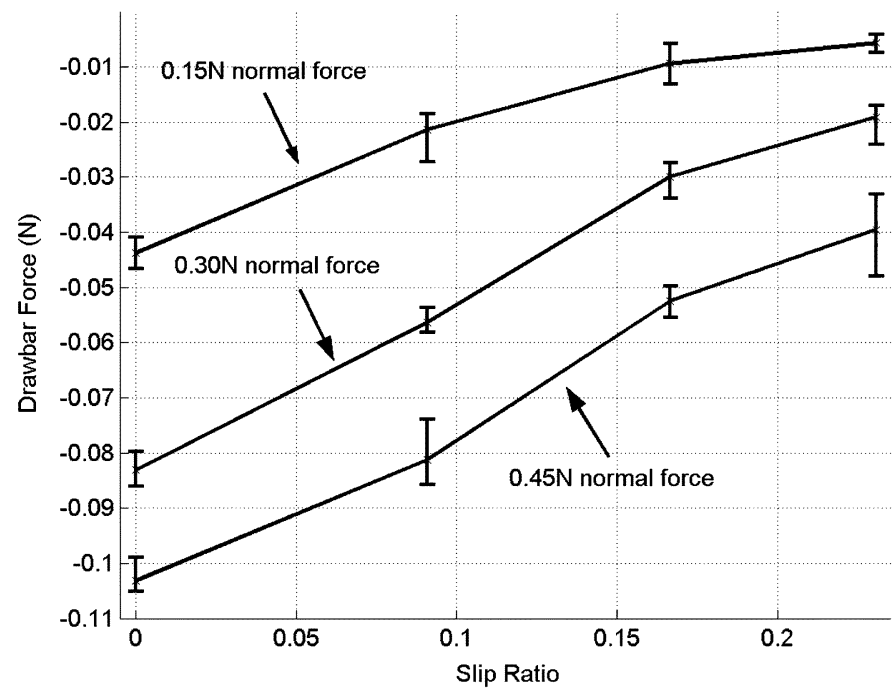

Fig. 14. Wheel experimental performance for the 20-mm diameter smooth wheel.

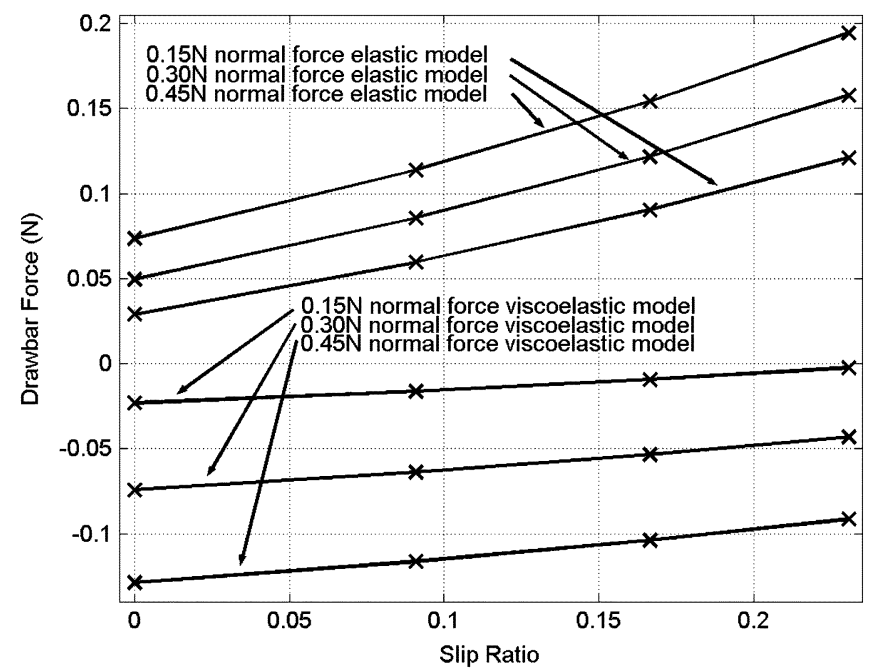

Fig. 15. Wheel model performance for the $15-\mathrm{mm}$ diameter smooth wheel.

\section{A. 15-mm Wheel}

The analytical models were first used to determine the expected drawbar forces for a smooth 15-mm diameter wheel moving on bovine liver, Fig. 15. Each line in the graph represents normal forces of $0.15,0.30$, or $0.45 \mathrm{~N}$. The experimentally determined values of viscosity ratio $(\mu / h)$, liver stiffness $(k)$, and liver damping $(b)$ as described in Section V, were used in the simulations.

As shown in Fig. 15, the elastic model predicts that a larger normal force will produce a larger positive drawbar force. The viscoelastic model predicts that a larger normal force will produce a larger negative drawbar force. This fundamental difference is due to the fact that for the elastic model, symmetry implies that the drawbar force is solely a function of the shear force produced. A larger normal force produces a larger vertical deformation and a larger contact length. This leads to a larger shear force in the horizontal direction and a larger positive drawbar force.

However, for the viscoelastic model, the drawbar force is not only a function of the shear force, but is also a function of the geometry of the membrane and liver tissue, which is asymmetric.

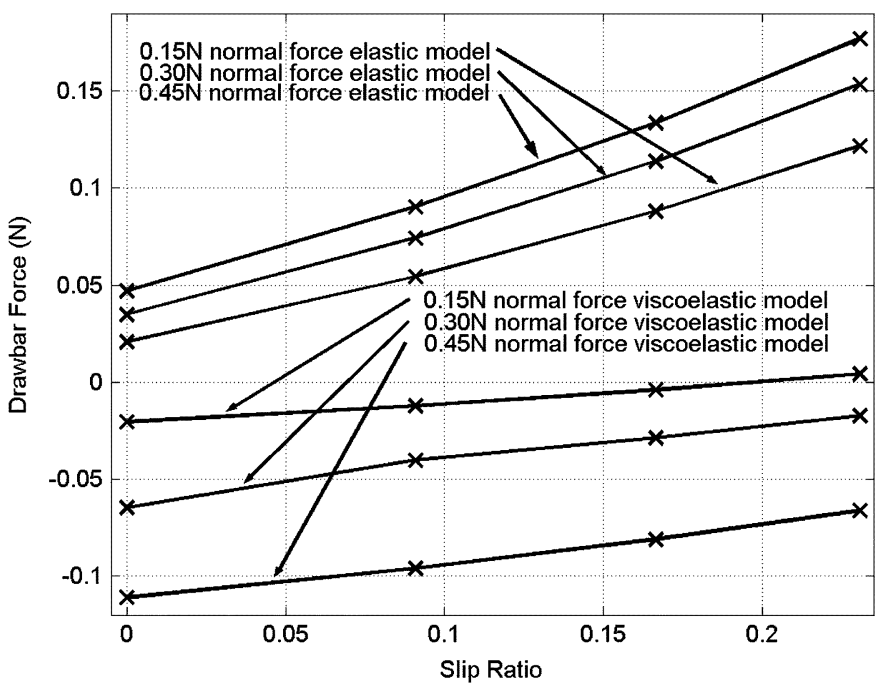

Fig. 16. Wheel model performance for the 20-mm diameter smooth wheel.

A larger normal force leads to a larger fore contact angle, with only a slightly larger aft contact angle. This larger fore angle implies that that the resultant force from the membrane tension will be directed in the negative $x$-direction (i.e., opposite the direction of motion). It also implies that the resultant force from the tissue pressure will be negative. For the $15-\mathrm{mm}$ diameter wheel, the shear force produced cannot compensate for these negatively directed forces, which leads to the negative drawbar force for the viscoelastic model.

It was also observed that the viscoelastic model (Fig. 15) closely approximates the experimental data for the $15-\mathrm{mm}$ diameter wheel (Fig. 13).

\section{B. 20-mm Wheel}

Similar results were found for the elastic and viscoelastic models when a 20-mm diameter wheel was used (Fig. 16). Slightly less positive drawbar forces were achieved with the elastic model, while slightly more positive drawbar forces were found using the viscoelastic model. This same trend exists in the experimental data presented in Section VI.

It can be concluded that the elastic model is inadequate, and the viscoelastic model more accurately predicts the wheel performance.

\section{EXPERIMENTAL RESULTS-WHEEL GEOMETRIES}

The preceding analytical and experimental studies confirm the models and give insight into the relationships between normal load, wheel diameter, and slip ratio. It was deduced that motion resistance caused by membrane deformation was significant, and the effects of wheel diameter and normal force are understood. However, there is a second phenomenon that contributes to overall wheel traction, and it is often significantly larger than the fluid shear forces created by interaction with the peritoneal fluid. This second phenomena arises from mechanical interactions between the wheel and the surface. These mechanical interactions can come from irregularities in the organ surface which cause physical engagement between the wheel and organ, or lead to local stress concentrations that change the viscous coefficient ratio (increasing $\mu / h$ in 


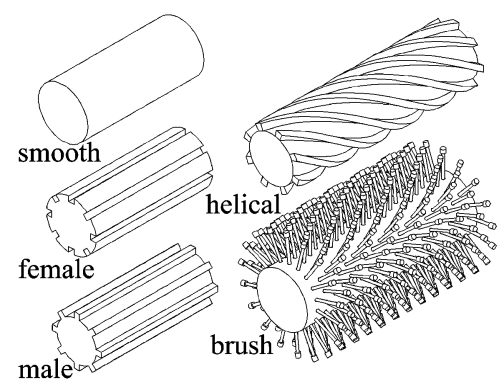

Fig. 17. Different wheel designs: smooth, female, male, helical, brush.

(9) by decreasing $h$ ). These factors are indirectly described by the above model, but are difficult to model in detail. Various wheel-tread geometries were analyzed experimentally to study these effects.

Wheel geometries shown in Fig. 17 were tested. The first wheel is the smooth wheel described by the analytical models and discussed in the previous sections. The second wheel ("female") has eight small grooves and eight grousers, while the third ("male") has larger grooves and more pronounced grousers. The fourth wheel ("helical") has eight small grooves that corkscrew around the wheel along the axis, and the fifth wheel ("brush") has a pattern of hairbrush bristles. The tests described above were repeated with each wheel on the bovine liver.

\section{A. Female Profile Wheel}

Fig. 18 shows experimental drawbar force measurements for the 15-mm diameter female wheel on bovine liver. This wheel should have a slight increase in contact pressure, but the same contact geometry, as compared with the smooth wheel, because the grooves decrease the contact area. The results show slightly larger, but similar, drawbar forces, compared with the smooth wheel. This confirms the effects of wheel geometry. However, traction forces are still low, because the traction is still predominately a result of fluid shearing (as in the smooth wheel case).

\section{B. Male Profile Wheel}

Fig. 19 shows experimental drawbar force measurements for the $15-\mathrm{mm}$ diameter male wheel on bovine liver. The performance of this wheel is different, compared with the female and smooth wheels. At low slip ratios, the drawbar force is negative. This force is increasingly negative for larger normal forces at low slip ratios. However, as the slip ratio increases, the drawbar force also increases. For higher slip ratios, larger normal force (heavier wheel) results in superior performance.

For low slip ratios, larger normal force produces greater sinkage, greater energy dissipation, and greater negative drawbar force. As the slip ratio increases, the negative resultant forces are overcome by the increased shear force created by higher contact pressures at the grousers and physical engagement between the organ and wheel, causing the drawbar force to become positive. The model suggests that this wheel geometry causes stress concentrations at the wheel-tissue interface (this would not be true with an elastic model/material). At these areas of high stress, it is believed that the peritoneal fluid layer is significantly reduced, and the wheel-tissue interaction

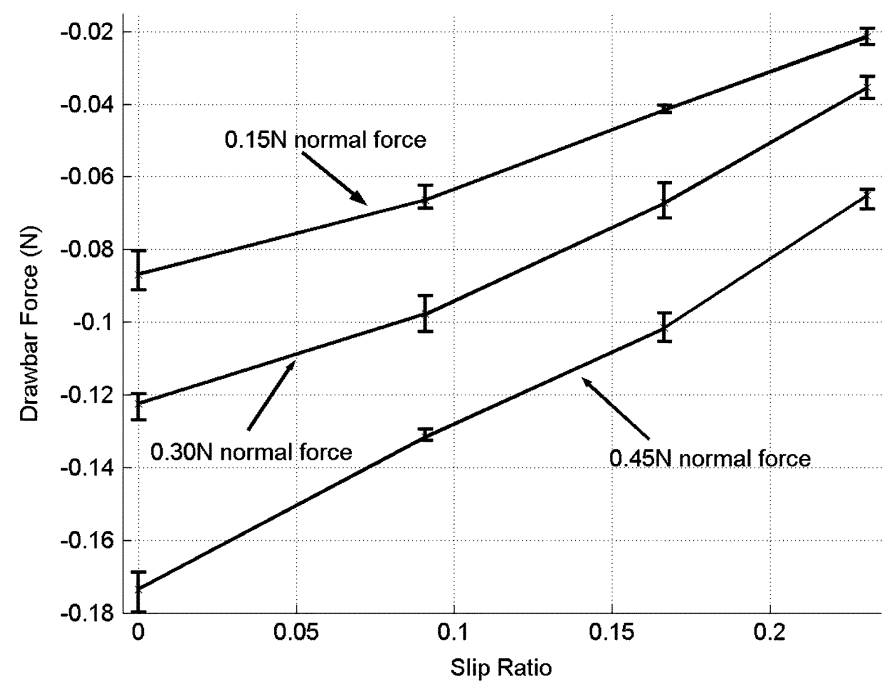

Fig. 18. Female wheel performance on bovine liver.

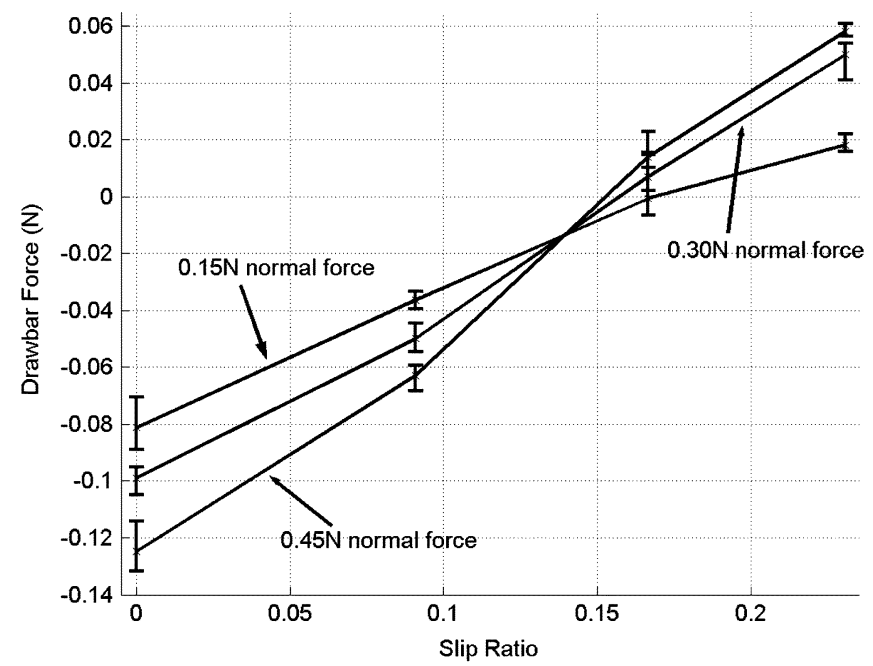

Fig. 19. Male wheel performance on bovine liver.

becomes governed by nonfluidic traction mechanics (i.e., it is dominated by mechanical traction effects). Thus, for these geometries and slip ratios, increasing the normal load increases the drawbar force.

At high slip ratios, this wheel produces drawbar forces that are approximately one-fifth the applied normal force. This implies that the male wheel should be capable of moving on the viscoelastic organs. However, with this small force production, it is not likely that a robot with these wheels would be capable of climbing a steeply inclined surface (as required in the in vivo environment).

\section{Helical Wheel}

Fig. 20 shows experimental drawbar force measurements for the 15-mm diameter helical wheel on bovine liver. This wheel's performance is similar to the male wheel. This is expected because the helical wheel design has the same profile as the male wheel, although in a corkscrew pattern.

The corkscrew profile allows the wheel to "channel" some of the tissue and fluid away while maintaining the local stress concentrations at the grousers. This allows such a design to produce 


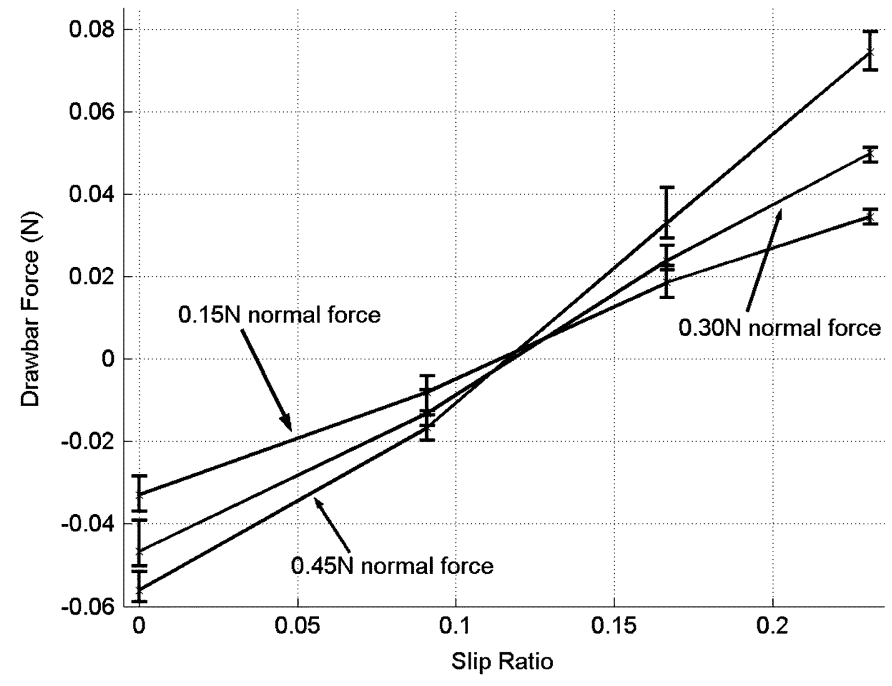

Fig. 20. Helical wheel performance on bovine liver.

drawbar forces slightly larger than the male wheel design. Thus, this wheel may perform better in vivo than the male wheel.

\section{Brush Wheel}

The 30-mm diameter brush wheel was designed to be pushed through a smaller diameter trocar for surgical applications, while maintaining a larger expanded diameter for in vivo functionality. The model above suggests that a larger diameter (for a given mass) leads to larger drawbar forces by reducing motion resistance. However, the fluid effects are thought to be mitigated by maintaining local stress concentrations at the tips of the bristles.

Fig. 21 shows experimental drawbar force measurements for the brush wheel on bovine liver. This wheel's performance is similar to the helical wheel's performance at high slip ratios. For low slip ratios, the helical design performs slightly better than the brush wheel. Also, the crossover point from negative drawbar force to positive drawbar force occurs at a higher slip ratio for the brush wheel $(\mathrm{SR}=0.17)$ than it does for the helical wheel $(\mathrm{SR}=0.12)$.

These results suggest that the helical wheel and brush wheel are leading candidates for attaining in vivo mobility. The helical wheel may have a slight advantage over the brush wheel based on the experimental data at low slip ratios. However, the brush wheel seems to have a better capability for climbing hilly terrain due to the larger expanded diameter.

\section{Crawler Performance}

The helical wheel design was tested ex vivo and in vivo using a prototype mobile robot (Fig. 1). This design is smaller and simpler, while producing the same drawbar force, compared with the brush wheel.

This prototype robot has two aluminum wheels that are directly attached to two 6-mm diameter permanent magnet dc motors. The motors are housed in cylindrical tubes with an outer diameter of $8.75 \mathrm{~mm}$. The inner and outer diameters of the wheel are 10.75 and $15 \mathrm{~mm}$, respectively. The helical profile of the wheels has a pitch of $30^{\circ}$ and a grouser depth of $1.5 \mathrm{~mm}$. The robot has a top speed of approximately $2 \mathrm{~cm} / \mathrm{s}$. The robot was

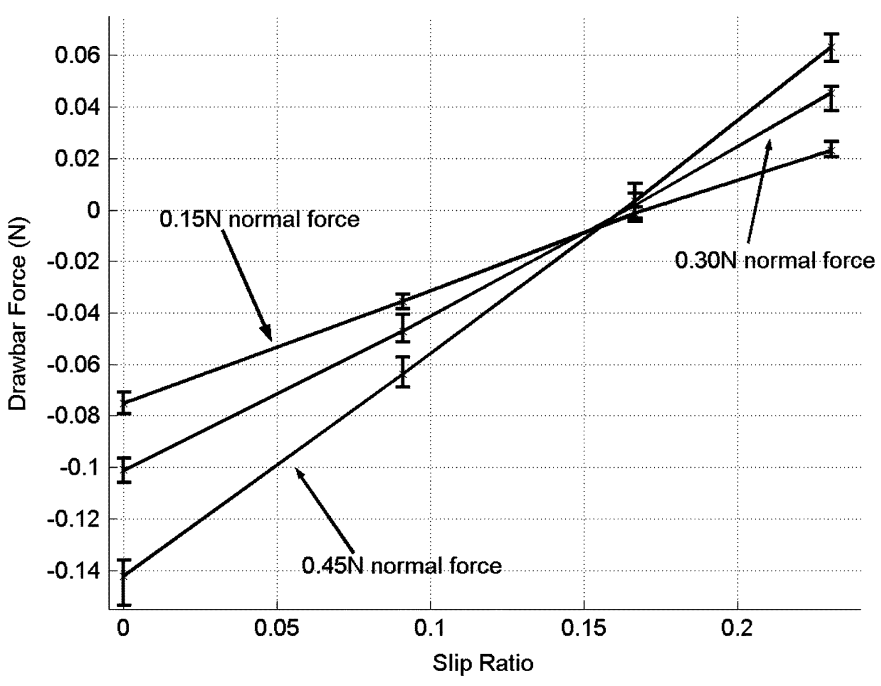

Fig. 21. Brush wheel performance on bovine liver.
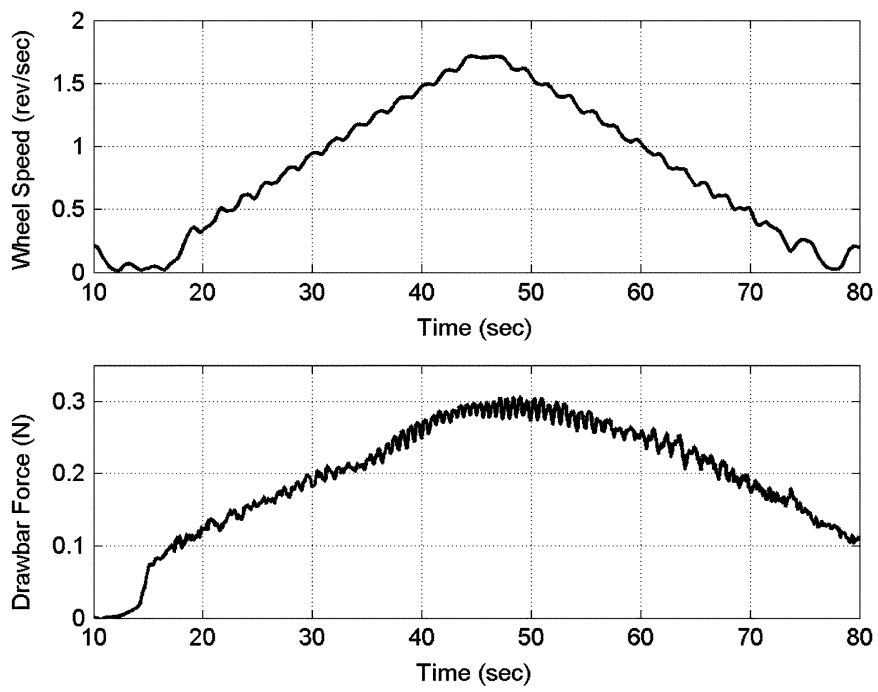

Fig. 22. Drawbar force for the helical wheel on bovine liver ex vivo.

tethered to a load cell to measure drawbar force at various wheel speeds. This test was performed ex vivo on bovine liver and in vivo on porcine liver, bowel, and spleen.

\section{A. Ex Vivo Drawbar Force}

The 15-mm diameter helical wheel was tested ex vivo on bovine liver. The mobile robot was tethered to a load cell to measure the force generation at various wheel speeds.

Results (Fig. 22) show that the robot is capable of producing a maximum drawbar force of $0.30 \mathrm{~N}$, which is equal to the robot's weight. This suggests that this robot, equipped with these wheels, would be able to traverse a slippery, inclined in vivo environment.

\section{B. In Vivo Drawbar Force}

This robot and wheel configuration was also tested in vivo on porcine small bowel (Fig. 2, bottom right). The preliminary results (Fig. 23) show a much-reduced drawbar force when compared with the ex vivo data. This is possibly due to the increase 

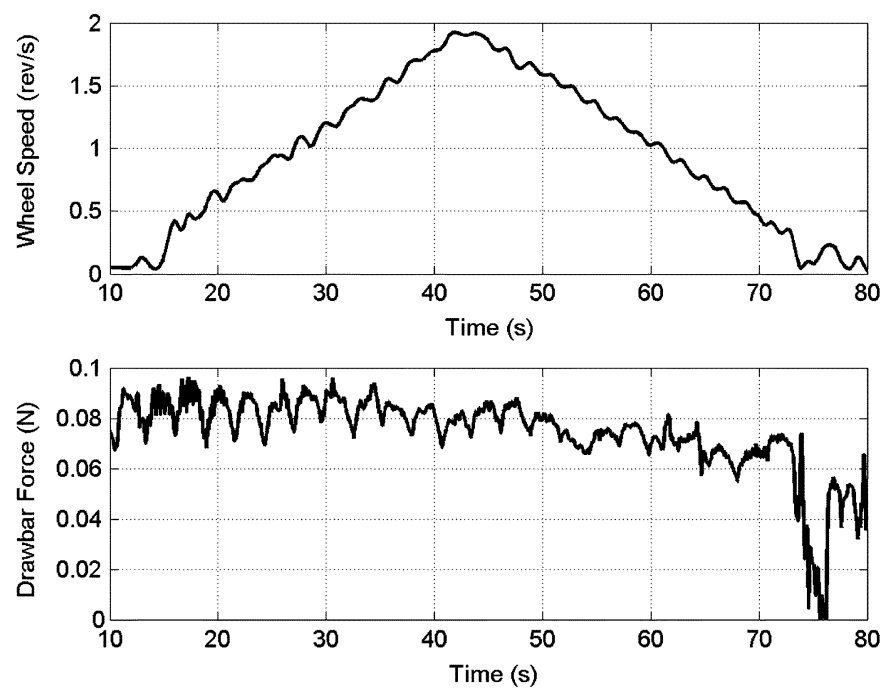

Fig. 23. Drawbar force for the helical wheel on porcine liver in vivo.

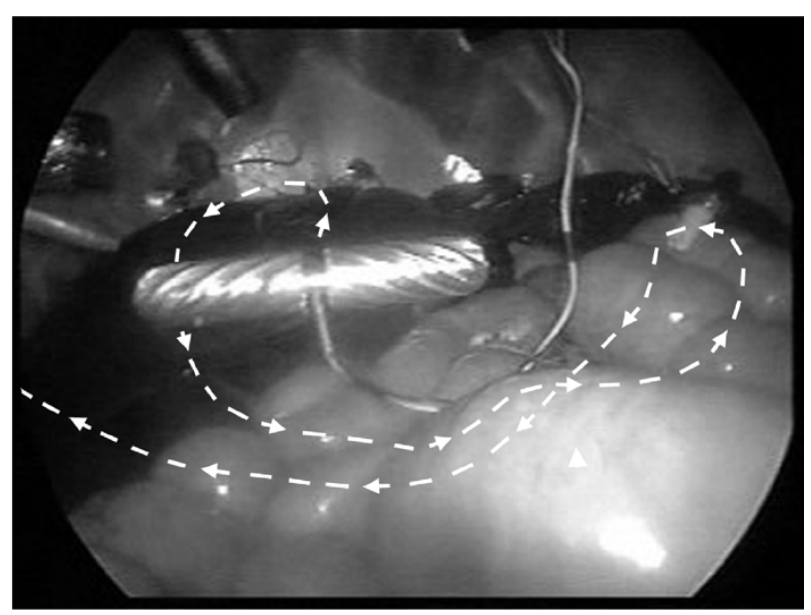

Fig. 24. Path traced by the $15-\mathrm{mm}$ crawler during porcine testing.

in membrane tension of in vivo living tissue, compared with ex vivo previously frozen tissue.

\section{In Vivo Maneuverability}

In vivo mobility testing with this and other similar prototype robots suggests that such a wheel design produces sufficient drawbar forces to maneuver within the abdominal environment. Recent in vivo porcine tests shows that the helical wheel design allows the robot to traverse all of the abdominal organs (liver, spleen, small, and large bowel), as well as climb organs two to three times its height. These tests were performed without causing any visible tissue damage. Video recorded during one of these tests was used to reconstruct the path traversed by the robot, a portion of which is illustrated in Fig. 24. The length of travel shown is approximately $0.5 \mathrm{~m}$, while the total distance traveled without assistance was approximately $1 \mathrm{~m}$ during this test.

\section{Discussion}

This paper presents an experimental and theoretical analysis of in vivo wheeled mobility. Viscoelastic analytical models of internal organs are presented that include the effects of the membrane tension and peritoneal fluid found in this environment. Laboratory experimental results help verify the simulation and identify two suitable wheel designs. Results from prototype robot drawbar force tests are also presented for ex vivo bovine liver and in vivo porcine bowel.

Simulation and experimental results show that better mobility is obtained on a viscoelastic organ by: 1) decreasing wheel sinkage (increasing wheel radius, robot length, or decreasing normal force); 2) creating local stress concentrations (increasing $\mu / h$ ); and/or by 3 ) creating mechanical interaction between the wheel and organ (penetration by the wheel of the fluid layer to the solid organ).

These results have helped lead to the development of a wheel that is capable of producing sufficient in vivo drawbar forces that allow for abdominal exploration without tissue damage. This wheel design has recently been successfully applied to a mobile camera robot that was used to explore and assist a surgeon during porcine tests. Current work focuses on developing a mobile robot with biopsy capability and a clamping mechanism. This work will potentially allow these types of robots to be used not only in a hospital setting, but also in extreme forward and/or hostile situations. Ultimately, they will allow a surgeon to be a remote first responder irrespective of the location of the patient.

\section{REFERENCES}

[1] M. Treat, "A surgeon's perspective on the difficulties of laparoscopic surgery," in Computer Integrated Surgery: Technology and Clinical Applications, R. Taylor, S. Lavallée, G. Burdea, and R. Mösges, Eds. Cambridge, MA: MIT Press, 1996, vol. 42, pp. 559-560.

[2] F. Tendick, R. Jennings, G. Tharp, and L. Stark, "Perception and manipulation problems in endoscope surgery," in Computer Integrated Surgery: Technology and Clinical Applications, R. Taylor, S. Lavallée, G. Burdea, and R. Mösges, Eds. Cambridge, MA: MIT Press, 1996, vol. 42, pp. 567-576.

[3] B. Wolfe, B. Gardiner, and B. Leary, "Endoscopic cholecystectomy: Analysis of complications," Arch. Surg., vol. 126, pp. 1192-1196, 1991.

[4] Southern Surgeons Club, "A prospective analysis of 1518 laparoscopic colecystectomies," New England J. Med., vol. 324, pp. 1073-1078, 1991.

[5] E. Schippers and V. Schumpelick, "Requirements and possibilities of computer-assisted endoscope surgery," in Computer Integrated Surgery: Technology and Clinical Applications, R. Taylor, S. Lavallée, G. Burdea, and R. Mösges, Eds. Cambridge, MA: MIT Press, 1996, vol. 42, pp. $561-566$.

[6] Medtech Insight, , Mission Viejo, CA, 2000.

[7] P. Lo et al., "Which laparoscopic operations are the fastest growing in residency programs?," Surg. Endoscopy, vol. 15, p. 145, 2001.

[8] J. Rosen, J. D. Brown, M. Barreca, L. Chang, M. Sinanan, and B. Hannaford, "The BlueDRAGON-A system of measuring the kinematics and dynamics of minimally invasive surgical instruments in vivo," in Proc. IEEE Int. Conf. Robot. Autom., Washington, DC, 2002, pp. 1876-1881.

[9] M. Rentschler, J. Dumpert, S. R. Platt, S. I. Ahmed, S. Farritor, and D. Oleynikov, "Mobile in vivo camera robots provide sole visual feedback for abdominal exploration and cholecystectomy," Surg. Endoscopy, to be published.

[10] R. M. Satava and S. B. Jones, "Surgical robotics: The early chronicles," Surg. Laparoscopy, Endoscopy, Percutaneous Tech., vol. 12, no. 1, pp. 6-16, 2002.

[11] G. H. Ballantyne, "Robotic surgery, telerobotic surgery, telepresence, and telementoring," Surg. Endoscopy, vol. 16, pp. 1389-1402, 2002.

[12] M. O. Schurr, G. Buess, B. Neisius, and U. Voges, "Robotics and telemanipulation technologies for endoscopic surgery," Surg. Endoscopy, vol. 14, pp. 375-381, 2000.

[13] J. Sackier and Y. Wang, "Robotically enhanced surgery: From concept to development," Surg. Endoscopy, vol. 8, pp. 63-66, 1994. 
[14] V. B. Kim, W. H. H. Chapman, R. J. Albrecht, B. M. Bailey, J. A. Young, L. W. Nifong, and W. R. Chitwood, "Early experience with telemanipulative robot-assisted laparoscopic cholecystectomy using da Vinci," Surg. Laparoscopy, Endoscopy, Percutaneous Tech., vol. 12, no. 1, pp. 33-44, 2002.

[15] P. Breedveld and S. Hirose, "Design of steerable endoscope to improve the visual perception of depth during laparoscopic surgery," J. Mech. Des., vol. 126, no. 1, pp. 2-5, 2004.

[16] H. Kang and J. T. Wen, "Robotic assistants aid surgeons during minimally invasive Procedures," IEEE Eng. Med. Biol., vol. 20, no. 1, pp. 94-104, Jan. 2001.

[17] N. A. Patronik, M. A. Zenati, and C. N. Riviere, "Crawling on the heart: A mobile robotic device for minimally invasive cardiac interventions," Lecture Notes Comput. Sci., vol. 3217, no. 1, pp. 9-16, 2004.

[18] L. Phee, D. Accoto, A. Menciassi, C. Stefanini, M. C. Carrozza, and P. Dario, "Analysis and development of locomotion devices for the gastrointestinal tract," IEEE Trans. Biomed. Eng., vol. 49, no. 6, pp. 613-616, Jun. 2002.

[19] M. Rentschler, A. Hadzialic, J. Dumpert, S. R. Platt, S. Farritor, and D. Oleynikov, "In vivo robots for laparoscopic surgery," Stud. Health Technol. Inf., vol. 98, pp. 316-322, 2004.

[20] D. Oleynikov, M. Rentschler, A. Hadzialic, J. Dumpert, S. R. Platt, and S. Farritor, "Miniature robots can assist in laparoscopic cholecystectomy," Surg. Endoscopy, vol. 19, no. 4, pp. 473-476, 2004.

[21] M. Rentschler, D. Oleynikov, A. Hadzialic, J. Dumpert, S. R. Platt, and S. Farritor, "In vivo camera robots provide improved vision for laparoscopic surgery," in Proc. Comput.-Assisted Radiol. Surg. Conf., Chicago, IL, Jun. 23-26, 2004, pp. 387-394.

[22] M. G. Bekker, Off the Road Locomotion. Ann Arbor, MI: Univ. Michigan Press, 1960.

[23] O. Onafeko and A. R. Reece, "Soil stresses and deformations beneath rigid wheel," J. Terramech., vol. 4, no. 1, pp. 59-80, 1967.

[24] J. Wong and A. Reece, "Prediction of rigid wheel performance based on the analysis of soil-wheel stresses, Part I. Performance of driven rigid wheels," J. Terramech., vol. 4, no. 1, pp. 81-98, 1967.

[25] T. Muro, "Tractive performance of a driven rigid wheel on soft ground based on the analysis of soil-wheel interaction," J. Terramech., vol. 30, no. 5, pp. 351-369, 1993.

[26] D. Wulfsohn and S. Upadhyaya, "Traction of low-pressure pneumatic tires in deformable terrain," SAE Trans., vol. 100, no. 2, pp. 348-363, 1991.

[27] J. Saliba, "Elastic-viscoplastic finite-element program for modeling tire/soil interaction," J. Aircraft, vol. 27, no. 4, pp. 350-357, 1990.

[28] T. Hiroma, S. Wanjii, T. Kataoka, and Y. Ota, "Stress analysis using FEM on stress distribution under a wheel considering friction with adhesion between a wheel and soil," J. Terramech., vol. 34, no. 4, pp. 225-233, 1997.

[29] E. Chen, J. Novakofski, W. Jenkins, and W. O’Brien, "Young's modulus measurements of soft tissues with application to elasticity imaging," IEEE Trans. Ultrasonics, Ferroelec., Freq. Control, vol. 43, no. 1, pp. 191-194, Jan. 1996.

[30] W. Yeh, Y. Jeng, H. Hsu, P. Kuo, M. Li, P. Yang, P. Lee, and P. Li, "Young's modulus measurements of human liver and correlation with pathological findings," in Proc. IEEE Ultrasonics Symp., vol. 2, 2001, pp. 1233-1236.

[31] K. Miller, "How to test very soft biological tissues in extension," $J$. Biomech., vol. 34, pp. 651-657, 2001.

[32] W. Ehlers and B. Markert, "A linear viscoelastic biphasic model for soft tissues based on the theory of porous media," ASME J. Biomech. Eng., vol. 123 , pp. 418-424, 2001.

[33] M. Rubin and S. Bodner, "A three-dimensional nonlinear model for dissipative response of soft tissue," Int. J. Solids Struct., vol. 39, pp. 5081-5099, 2002.

[34] J. Rosen, B. Hannaford, M. MacFarlane, and M. Sinanan, "Force controlled and teleoperated endoscopic grasper for minimally invasive surgery-Experimental performance evaluation," IEEE Trans. Biomed. Eng., vol. 46, no. 10, pp. 1212-1221, Oct. 1999.

[35] J. D. Brown, J. Rosen, Y. S. Kim, L. Chang, M. N. Sinanan, and B. Hannaford, "In-vivo and in-situ compressive properties of porcine abdominal soft tissues," Stud. Health Technol. Inf., vol. 94, pp. 26-32, 2003.

[36] T. Chanthasopeephan, J. Desai, and A. Lau, "Measuring forces in liver cutting for reality-based haptic display," in Proc. IEEE Int. Conf. Intell. Robots Syst., vol. 3, 2003, pp. 3083-3088.

[37] H. Visser, E. A. M. Heijnsdijk, J. L. Herder, and P. V. Pistecky, "Forces and displacements in colon surgery," Surg. Endoscopy, vol. 16, pp. 1426-1430, 2002.
[38] M. Rentschler, J. Dumpert, A. Hadzialic, S. Platt, D. Oleynikov, K. Iagnemma, and S. Farritor, "Theoretical and experimental analysis of in vivo wheeled mobility," in Proc. ASME 28th Biennial Mech. Robot. Conf., vol. 2, 2004, pp. 1241-1249.

[39] A. P. S. Selvadurai, Elastic Analysis of Soil-Foundation Interaction. New York: Elsevier, 1979.

[40] Y. C. Fung, Biomechanics: Mechanical Properties of Living Tissues. New York: Springer-Verlag, 1981.

[41] D. Young, B. Munson, and T. Okiishi, Fluid Mechanics. New York: Wiley, 1997.

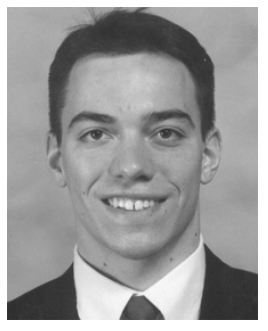

Mark E. Rentschler received the B.S. degree from the University of Nebraska, Lincoln, in 2001, and the M.S. degree from the Massachusetts Institute of Technology (MIT), Cambridge, in 2003, both in mechanical engineering. He is currently working toward the Ph.D. degree in biomedical engineering at the University of Nebraska, Lincoln.

His research interests include surgical robotics and tissue mechanics.

While at MIT, Mr. Rentschler was a National Defense Science and Engineering Graduate Fellow.

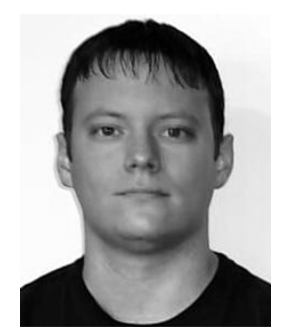

Jason Dumpert received the B.S. degree in in 2001, and the M.S. degree in 2004, both in electrical engineering, from the University of Nebraska, Lincoln, where he is currently working toward the Ph.D. degree in biomedical engineering.

His research interests include mobile robotics and surgical robotics.

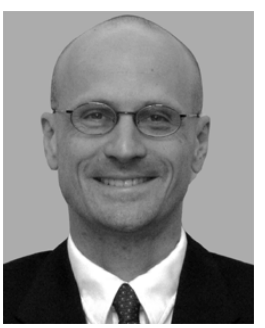

Stephen R. Platt received the B.A. degree in physics and astronomy from Williams College, Williamstown, MA, in 1983, the M.S. and Ph.D. degrees in astronomy and astrophysics from the University of Chicago, Chicago, IL, in 1991, and the M.S. degree in mechanical engineering from the University of Nebraska, Lincoln, in 2003.

$\mathrm{He}$ is currently a Research Assistant Professor with the Department of Mechanical Engineering, University of Nebraska, Lincoln. His interests include biomedical sensors, surgical robotics, and millimeter-wave detector systems for observational astrophysics applications.

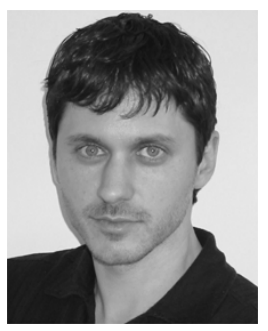

Karl Iagnemma received the B.S. degree from the University of Michigan, Ann Arbor, and the M.S. and $\mathrm{Ph} . \mathrm{D}$. degrees from the Massachusetts Institute of Technology (MIT), Cambridge.

Currently, he is a Research Scientist with the Mechanical Engineering Department, MIT. Previously, he had been a Visiting Researcher at the NASA Jet Propulsion Laboratory, Pasadena, CA, and had performed postdoctoral research at MIT. His primary research interests are in the areas of sensing, motion planning, and control of mobile robots in outdoor terrain, including modeling and analysis of robot-terrain interaction. He is author of the monograph, Mobile Robots in Rough Terrain: Estimation, Planning and Control with Application to Planetary Rovers (New York: Springer, 2004).

While at MIT, Dr. Iagnemma was a National Science Foundation Graduate Fellow. 


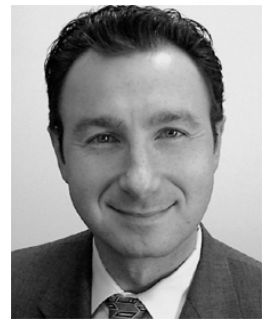

Dmitry Oleynikov is board certified in General Surgery and is currently an Assistant Professor and Director of the Education and Training Center for Minimally Invasive and Computer Assisted Surgery with the University of Nebraska Medical Center, Lincoln. He is also an Adjunct Assistant Professor of Engineering with the University of Nebraska, Lincoln.

He completed his surgical residency at the University of Utah Medical Center, Salt Lake City, in 2000. After residency, he served as Acting Instructor and Senior Fellow at the Center for Videoendoscopic Surgery, Department of Surgery, University of Washington School of Medicine, Seattle.

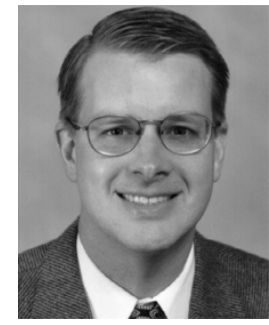

Shane Farritor received the B.S. degree from the University of Nebraska, Lincoln, in 1992, and the M.S. and Ph.D. degrees in mechanical engineering from the Massachusetts Institute of Technology, Cambridge, in 1998.

$\mathrm{He}$ is currently an Associate Professor of Mechanical Engineering with the University of Nebraska, Lincoln, and holds courtesy appointments in both the Department of Surgery and the Department of Orthopaedic Surgery, University of Nebraska Medical Center, Lincoln. His research interests include space robotics, surgical robotics, biomedical sensors, and robotics for highway safety. He also serves as Chairman of the AIAA Space Robotics and Automation Technical Committee. 